\title{
The Man Made Global Warming - Energetic Scenarios
}

\author{
Roberto Visentin \\ Department of Physics, Engineering Faculty, Università della Calabria, Cosenza, Italy \\ Email address: \\ martavisentin68@gmail.com

\section{To cite this article:} \\ Roberto Visentin. The Man Made Global Warming - Energetic Scenarios. American Journal of Environmental Protection. \\ Vol. 7, No. 5, 2018, pp. 63-69. doi: 10.11648/j.ajep.20180705.11
}

Received: September 20, 2018; Accepted: October 31, 2018; Published: November 19, 2018

\begin{abstract}
In many international meetings, energy saving programs have been suggested against the man made global warming effects, produced by the consumptions of the fossil derived energies. The FDE (Fossil Derived Energies) consumptions are due to the world's consumers whose number grows at a mean rate of 0.062 billion units/year: this growing number asks a greater number of goods to be consumed. The saving energy programs fail because the consumptions of goods demand provokes a growth of the production that is of the FDE burned. The MMGW (Man Made Global Warming) continues to grow and a catastrophic geostorm is in charge. In addition the FDE reserves continue to be eroded by the consumptions. A substitutive energetic economy, no IRG (Infrared reflecting Gases) producer, is the proposal to be discussed. To built this energetic economy takes time and it could be delayed when the atmosphere memory effect is considered. The substitutive energetic economy could have the following properties: prompt to match the MMGW, able to produce the equivalent of an intense saving energy program without reducing the consumptions, a competitive price of the energy offered to the consumers, a low investment cost at the year 2018. 11.3\% of the world's population consumes 30\% of FDE with a per capita FDE consumed of 5.1 TEP (Ton of Equivalent Petroleum) /year. The remaining $88.7 \%$ consumes the $70 \%$ of FDE/year. The MMGW is, then produced as a global effect. A comparative analysis of the hypothetical scenarios which can be considered has been made. The less delayed against MMGW effects of long duration and economically sustainable resulted hard solar wind energy producer system, when the produced energy is consumable on demand. Either the electrolytic hydrogen gas production or the hydrostorage have been successfully tested to transform the stochastic into on demand consumable energy. Going on with the analysis of the HSW (Hard Solar Wind) stored energy supply, an equivalent energy saving of 27.7\% (2017-2117) without diminishing the consumptions of goods and a mean low price of the equivalent petroleum barrel substituted, 42 USD/barrel have been obtained.
\end{abstract}

Keywords: Fossil Derived Energies, Man Made Global Warming, Infrared Reflecting Gases, Normal Cubic Meter, Hard Solar Wind, Low Cost Strategy, Ton of Equivalent Petroleum

\section{Introduction}

The planetary development, at the year 2018 is sustained for $85 \%$ by the FDE energies (coal, natural gas, oil), $10 \%$ by hydroelectricity, $5 \%$ atomic energy, main contributions.

The FDE burned produce IRG which are pumped in the atmosphere whose infrared reflecting power augments. In so doing the earth' surface temperature augments and hard climatic effects happen, MMGW [1].

The FDE consumed depend from the number of the earth's population; this number continues to grow at a mean rate of 0.062 billion units/year. The preasumed economically exploitable FDE reserves have been estimated 1228 billion
TEP at the year 2017 [3].

Before the year 2080 the FDE will have a not sustainable price USD/TEP and they will be almost exhausted. The socio economic effects of this situation will be warned already around the year 2030 (MIT-USA, 1980).

\section{Method}

\subsection{Excess IRG in Atmosphere}

The IRG excess stays in the atmosphere for more than a century. Then all the IRG pumped in the atmosphere in the time period 1981-2081 are summed as an excess. The distribution of the excess IRG in the atmosphere (1956-2181) 
is shown in table 1 (see also table 2).

Table 1. Excess IRG in the atmosphere (weight) man made global warming.

\begin{tabular}{llll}
\hline $\mathbf{1}$ & $\mathbf{2}$ & $\mathbf{3}$ & $\mathbf{4}$ \\
\hline $1956-1981$ & 331 & 331 & +13 \\
$1981-2017$ & 784 & 1115 & +43 \\
$2017-2047$ & 916 & 2031 & +79 \\
$2047-2081$ & $1264-331$ & 2964 & +115.5 \\
$2081-2117$ & -784 & 2211 & +86 \\
$2117-2147$ & -916 & 1294 & +50 \\
$2147-2181$ & -1294 & 0 & 0 \\
\hline
\end{tabular}

Column 1 Time, years

Column 2 Excess of IRG in atmosphere distribution $\times 10^{9}$ ton (negative numbers indicate the excess IRG exhausted after one century)

Column 3 Total excess of IRG in atmosphere $x 10^{9}$ ton

Column 4 Column 3/2566; 2566 billion tons are the carbon dioxide weight in the atmosphere. It regulates the surface earth's mean temperature around $15^{\circ} \mathrm{C}$. The added IRG modify the atmosphere Infrared Reflectivity, and the earth' surface temperature augments; the catastrophic planetary geostorm is in charge and it will explode with a multiplicative self effect.

In preparing table 1 the following hypothesis have been made:

a) the sea absorbs $50 \%$ of the IRG excess produced

b) the IRG excess absorbed by the green plantation is negligible

c) the excess carbon dioxide produced is enhanced by a factor 1.2, to take into account of the added NOx IRG produced (airplanes, agriculture)

d) from each TEP of FDE burned in air 3.14 ton of carbon dioxide are produced

\subsection{The Fossil Derived Energies Consumed}

In table 2 are shown the FDE consumed from 1956 to 2081 (preasumed FDE exhaustion year) when the mean earth's population grow rate is 0.062 billion units/year and the mean FDE per capita consumed is $2.16 \mathrm{TEP} /$ year (year 2017).

Table 2. FDE consumed from 1956.

\begin{tabular}{llll}
\hline $\mathbf{1}$ & $\mathbf{2}$ & $\mathbf{3}$ & $\mathbf{4}$ \\
\hline $1956-1981$ & $(5.39+8.7) \times 0.5 \times 25$ & 176 & 1644 \\
$1981-2017$ & $(8.7+14.45) \times 0.5 \times 36$ & 416 & 1228 \\
$2017-2047$ & $(14.45+18) \times 0.5 \times 30$ & 486 & 742 \\
$2047-2081$ & $(18+21.46) \times 0.5 \times 34$ & 671 & 71 \\
\hline
\end{tabular}

Column 1 Time, years

Column 2 FDE consumed $\times 10^{9}$ TEP

Column 3 FDE consumed $\times 10^{9}$ TEP

Column 4 FDE reserves $\times 10^{9}$ TEP

Several proposals of energy saving have been presented at international meetings: all have failed. Nevertheless the MMGW augments its effects, while the FDE reserves continue to be eroded by the planetary consumptions (wars included).

\subsection{The Substitutive Energetic Economy}

On the frame here presented, the substitutive planetary energetic economy could be considered, sustained by no infrared reflecting gas emitters low cost energies.

Table 3. Substitutive planetary energetic economy.

\begin{tabular}{|c|c|}
\hline Environment air conditioning - heat pump & Electricity \\
\hline Cooking - Electric induction plates & Electricity \\
\hline Environment and street light - low electricity consumed lamps & Electricity \\
\hline \multicolumn{2}{|l|}{ Private transportation } \\
\hline Electric city car & Electricity \\
\hline Electric road car & Electricity \\
\hline Hybrid car & Fuel \\
\hline Motorcycles & Fuel-Electricity \\
\hline Lorries & Fuel-Electricity \\
\hline Other applications & Fuel \\
\hline \multicolumn{2}{|l|}{ Collective transportation } \\
\hline Citybus & Fuel-Electricity \\
\hline Roadbus & Fuel-Electricity \\
\hline Airplane & Fuel \\
\hline \multicolumn{2}{|l|}{ Industry and services consumptions } \\
\hline Hydrogen for industrial uses & Electricity \\
\hline Energy consumptions & Fuel - Electricity \\
\hline
\end{tabular}

From table 3 it follows that the substitutive energetic economy consumes mainly electricity. The fuels require electricity to produce electrolytic hydrogen which is made to react with carbonium which could be derived from coal. Then synthetic liquid fuels are available as substitute of the oil derived fuels. There are consumptions sectors which will continue to consume liquid fuels*.

\subsection{The Man Made Global Warming}

The MMGW produces hard climatic effects which can not be cancelled. The atmosphere memory has already stored an excess of IRG which at the year 2017 was 1115 billion ton, 
$43 \%$ of the atmosphere carbon dioxide weight (table 1 ). This excess IRG continues to stay in the atmosphere and is added to the other IRG excess (table 1). The expectation that a substitutive energetic economy, which corrects the MMGW, could be organized in a short time is far from the reality, as well as the convinction that the climatic change, produced by the MMGW, has to be sustained as the price to be payed for the development. More hard effects have to be expected, when the IRG growth is near to double the carbon dioxide of the atmosphere (table 1); the explosion of a selfsustained catastrophic planetary geostorm will continue longer the FDE exhaustion time, with hard socio economic consequences to be payed [1].

*There are 10000 billion Ton of Equivalent geological
Coal [3]; the percent exploitable and the cost of these earth's reserves are not known. From the harvest of energetic biomass, cultivated in the allowed surface area between the wind convertors (short rotation cultivated energetic biomass like brooms) can be obtained several billion litres/year of liquid synthetic fuels (subsitute of oil derived fuels) to be consumed for an indefinite time length (carbonium from energetic biomass $25 \%$ weight).

\subsection{IRG Excess in Atmosphere When Stored hard Solar Is in Progress}

In table 4 is shown the IRG excess in atmosphere when stored hard solar proliferation is in progress**

Table 4. IRG excess in atmosphere when stored hard solar is in progress.

\begin{tabular}{|c|c|c|c|c|c|}
\hline 1 & 2 & 3 & 4 & 5 & 6 \\
\hline 1956-1981 & & 176 & 331 & 331 & +13 \\
\hline $1981-2017$ & & 416 & 784 & 1115 & +43 \\
\hline $2017-2047$ & 84.5 & 401 & 756 & 1871 & +73 \\
\hline $2047-2081$ & 394 & 277 & $-331+522$ & 2061 & +80 \\
\hline $2081-2117$ & 719 & - & -784 & 1277 & +50 \\
\hline $2117-2147$ & 763 & - & -756 & 522 & +20 \\
\hline $2147-2181$ & 884 & - & -522 & 0 & 0 \\
\hline
\end{tabular}

**other energetic productions no IRG emitters have been tested too by assuming hypotethic performances of the convertors and supposed valid energy reserves. They have expectation time more delayed against MMGW, and when proliferation is considered, a probable fuel shortage in the short medium term or too high cost.

Column 1 Time, years

Column 2 Substitutive energy produced by stored hard solar $\times 10^{9} \mathrm{TEP}$

Column 3 FDE consumed $\times 10^{9}$ TEP

Column 4 IRG added $\times 10^{9}$ ton

Column 5 Total IRG excess in the atmosphere $\times 10^{9}$ ton

Column $6 \%$ of total carbon dioxide in the atmosphere

At the year 2017 there are 1115 billion ton of IRG excess in the atmosphere which can not be cancelled, because produced before the year 2022 (assumed year of HSW).

In the start assumed hypothesis, the IRG excess in atmosphere is reduced of 1997 billion ton in the time period 2017-2117 with the effect of $27.7 \%$ equivalent energy saving program (per year from 2017 to 2117) without reducing the consumptions. The IRG excess continues to exist also later the year 2081 (atmosphere memory). Table 4 shows the more ready action against MMGW feasible by avoiding to waste money and to reduce the number of jobs.

\subsection{The Substitutive Energy to Sustain the Consumptions on the Globe}

To sustain the consumptions, when the FDE reserves are exhausted are necessary time, great investments and hard transformation of the habits (table 3) which will be favoured when a safe and low cost planetary perspective will be offered. On these directions many research efforts are made on the world on the engineering of energetic devices, consuming energies no IRG emitters (hard solar-atomic fusion).



Figure 1. Diagram of the modular hydrogen stored farm and of the modular hydrostored farm. 
A proliferation to produce substitutive energy requires time, proved convertors and a market of sustainable and stable prices of the energy offered. Several authors [2] have considered the perspectives of hard solar more advanced of other competitors to produce the energy of the economy of table 3 . These analysis, dated 1980, could not take advantage from the experiences aquired after this date, with a running which tested the decommission time lenght of hard solar technologies, and renews the role of wind convertors as the most suited for economic hard solar proliferation to produce huge energy quantities. To consume on demand the stochastic energy, produced by terrestrial hard solar wind convertors, two main methods have been tested:

a hydrogen production (Figure 1)

b hydro storage (Figure 1)

When hydrogen is produced hard solar stochastic electricity is consumed on demand as a gas (from which electricity can be again obtained) when hydro storage is used, the hard solar stochastic electricity is consumed on demand as hydro electricity (Figure 1). Hard solar is a proved energetic technology, it can consume, as a fuel, the abundant silicates reserves of the earth's crust or easily $100 \%$ recyclable materials of which it can be made, in proliferation consumes the minimum prohibited areas, do not produces dangerous wastes, the stochastic energy produced can be transformed in energy on demand consumed; it is almost innocuos.

These properties suggest to verify the economic frame on which competitive energy prices can be obtained and the contribution against MMGW.

\subsection{Low Cost Strategy Operative from Year 2022}

In table 5 is the energy produced, $26 \times 10^{9} \mathrm{TEP} / \mathrm{year}$ in the regime phase, when the low cost strategy is operative from year 2022 (see also the Appendix).*

Table 5. Substitutive energy no IRG emitter from stored hard solar low cost strategy operative from 2022.

\begin{tabular}{lllllll}
\hline $\mathbf{1}$ & $\mathbf{2}$ & $\mathbf{3}$ & $\mathbf{4}$ & $\mathbf{5}$ & $\mathbf{6}$ \\
\hline $1981-2017$ & & & & & \\
$2017-2047$ & 43465 & 84.5 & 514 & 76 & 0.13 \\
$2047-2072$ & 81501 & 247 & 330 & 293 & 0.082 \\
$2072-2097$ & 119837 & 409 & 276 & 43 & 0.073 \\
$2097-2122$ & 157873 & 572 & 234 & 41 & 0.069 \\
$2122-2147$ & 152144 & 650 & 34 & 613 & 0.058 \\
\hline
\end{tabular}

Column 1 Time, years

Column 2 Total expenses $\times 10^{9}$ USD (see Appendix)

Column 3 Consumable on demand energy produced $\times 10^{9}$ TEP

Column 4 Market price of substitutive TEP produced, which pay the expenses of column 2 USD/TEP

Column 5 Market price of the equivalent oil barrel produced USD/barrel

Column 6 Market price of the electricity produced USD/KWhe

Column 7 FDE reserves $\times 10^{9}$ TEP

*Year 2100, $12.6 \times 10^{9}$ (population) x 2.2 (per capita consumptions $)=27.72 \times 10^{9} \mathrm{TEP} /$ year $-1.7 \times 10^{9} \mathrm{TEP} /$ year (hydroelectricity) $=26 \times 10^{9} \mathrm{TEP} /$ year to be produced.

The total expenses sustained in the transition time period 2022-2147 year (554820 x10 ${ }^{9}$ USD, table 5) can be payed with a mean equivalent barrel price of $42 \mathrm{USD} /$ barrel, while after the year 2147 at lower price as 34 USD/barrel and lower. This mean price is stable and very low, it could sweep away the resistance of energy prices derived from other fuels and the hard solar could become the most favourable energy.

The effect of the low cost strategy is in the sequence $\mathrm{C}$, $\mathrm{C}+\mathrm{R}, \mathrm{C}+2 \mathrm{R}, \mathrm{C}+3 \mathrm{R}, 4 \mathrm{R}$ (see the Appendix). The hard solar here described exibits an efficiency of $32.8 \%$, when energy consumed on demand is compared with the stochastic energy produced.

The abundance of the reserves (concrete or the reuse) allow to move far in the time the extinction of the material reserves; then stable energy prices have to be expected.**

**In the hypothesis that all the stakes of wind convertors are made of concrete the total concrete is (3500 ton/stake) $6.345 \times 10^{10}$ ton of which silicates derived materials 2.54 $\mathrm{x} 10^{10}$ ton. $1 \%$ of the earth's crust silicates reserves are 74.7 $\mathrm{x} 10^{13}$ ton. Then to consume this $1 \%$ it has to be made 29400 decommissions of all stakes each one every 200 years. Better perspectives are offered by the stakes made of iron (abundant $100 \%$ recyclable material) [5].

\subsection{The Oxygen Credit}

In table 6 is valued the oxygen credit income derived from the market exchange of the pure electrolytic oxygen gas produced. This income can help to sustain the necessary expenses for managing, mainteinance, repair, surveillance, of the whole energetic system.

The hypothesis in table 6 are:

(1) mean number of jobs payed $0.35 \mathrm{job} / \mathrm{MWep}$

(2) mean revenue per job $20000 \mathrm{USD} /$ year (all included)

(3) market price of the oxygen gas $0.0565 \mathrm{USD} / \mathrm{NCM}$ 
Table 6. Oxygen credit.

\begin{tabular}{llllll}
\hline $\mathbf{1}$ & $\mathbf{2}$ & $\mathbf{3}$ & $\mathbf{4}$ & $\mathbf{5}$ & $\mathbf{6}$ \\
\hline $2022-2047$ & 99412 & 1 & 4208 & 1404 & 8416000 \\
$2047-2072$ & 290586 & 0.64 & 7890 & 2635 & 15780000 \\
$2072-2097$ & 481761 & 0.56 & 11574 & 3865 & 23148000 \\
$2097-2122$ & 672936 & 0.54 & 15256 & 5095 & 30512000 \\
$2122-2147$ & 764700 & 0.47 & 15256 & 5095 & 30512000 \\
\hline
\end{tabular}

Column 1 Time, years

Column 2 Oxygen produced $\times 10^{9} \mathrm{NCM}$

Column $3 \%$ of oxygen volume sold at a price of $0.0565 \mathrm{USD} / \mathrm{NCM}$

Column 4 Added job cost $\times 10^{9}$ USD

Column 5 Added expenses $\times 10^{9}$ USD

Column 6 Max number of jobs payed (natural, artificial intelligences)

The water electrolysis is the best hydrogen plus oxygen producer when stochastic electricity has to be exploited. The electrolysis production has not a threshold.

\section{Results}

The low cost strategy is well tailored to HSW energetic system, and the cost of its construction can be self-sustained by the energy sold at a very low market price, without interrupt the energy supply.

LCS introduces an innovative economic method to save money. It regulates all the phases of:

(1) energetic and control components production

(2) construction in field

(3) management of the energy produced

The characteristic rate assumed for HSW energetic system is $4 \% / y e a r$, rate of all the short amortization time lenghts.

\section{Conclusions}

This work demonstrates that energy on demand, from stochastic energy obtained by proliferating hard solar terrestrial convertors, can sustain planetary consumptions, when the earth's population is 12.6 billion and the total energy per capita consumed is $2.2 \mathrm{TEP} / \mathrm{year}$, for an indefinite time lenght with stable and competitive prices of the energy produced. All the investments, regulated by the low cost strategy, can be payed by the energy produced and sold at low market prices.

The low cost strategy, when applied to terrestrial hard solar, allows the energy production without interruption of the supplying in the programmed decommission phases. By using to advantage the oxygen credit can be payed the revenue of a mean 0.35 job/MWep for activities of managing, mainteinance, repair, surveillance to natural and artificial intelligences.

\section{Acknowledgements}

I mention Marta Visentin (naturalist - degree in 2003 in Natural Sciences La Sapienza University, Roma Italy) and Alfonso Verrillo (degree in 1994 in Medicine and Surgery specialization in 1999 in nuclear Medicine - Catholic
University Roma, Italy) for their continuous encouragement and help.

\section{Appendix}

\section{Appendix 1. Costs Assumed (All Included)}

$\begin{array}{ll}\text { Energetic convertors } & 1.725 \times 10^{6} \mathrm{USD} / \mathrm{MWep} \\ \text { Bricks } & 80 \mathrm{USD} / \text { ton } \\ \text { Concrete } & 130 \mathrm{USD} / \text { ton } \\ \text { Stainless s. } & 1500 \mathrm{USD} / \text { ton } \\ \text { Iron } & 130 \mathrm{USD} / \text { ton } \\ \text { Smart grid } & 600000 \mathrm{USD} / \mathrm{Km} \\ \text { Electrolytic facility } & 0.11 \mathrm{USD} / \mathrm{NCM} \text { (production power) } \\ \text { Water elevators } & 25000 \mathrm{USD} / \mathrm{MWe} \\ \text { Jobs mean revenue } & 20000 \mathrm{USD} / \text { job, year }\end{array}$

Cost of Iron or concrete in wind stakes assumed $10 \%$ of the energetic convertors expenses

\section{Appendix 2. On demand Energy Consumed from Stochastic Produced}

a. total $26 \times 10^{9} \mathrm{TEP} / \mathrm{year}$, on demand

b. equivalent electricity $104000 \times 10^{9} \quad$ KWhe/year, consumed by the substitutive energetic economy of table 3 ( $4000 \mathrm{KWh} / \mathrm{TEP}$ oil-thermoelectric equivalent)

c. from hydrogen stored hard solar $87 \%, 90480 \times 10^{9}$ KWhe/year

d. from hydrostored hard solar $13 \%, 13520 \times 10^{9}$ KWhe/year

e. hydrogen fuel to produce $90480 \times 10^{9} \mathrm{KWhe} / \mathrm{year}$ by turbo convertors hydrogen fueled $61176 \quad \times 10^{9}$ $\mathrm{NCM} /$ year (1.479 KWhe/NCM)

f. stochastic electricity to produce $61176 \times 10^{9} \mathrm{NCM} /$ year of electrolytic hydrogen fuel $301498 \times 10^{9} \mathrm{KWhe} /$ year (4.93 KWhe/NCM)

g. hydro stored stochastic electricity to produce 13520 x $10^{9} \mathrm{KWhe} /$ year on demand $15191 \times 10^{9} \mathrm{KWhe} / \mathrm{year}$, stochastic

h. total stochastic electricity to be produced $316789 \times 10^{9}$ KWhe/year ${ }^{1}$

i. electricity produced by a 5 MWep wind unit $5 \times 3900 \times$ $0.95 \times 0.95 \times 0.99=17422762 \mathrm{KWhe} /$ year (stochastic) $^{2}$

j. number of wind convertors (planetary wind park) 
18182479 units, 5 MWep each ${ }^{3}$

k. total wind power $90912394 \mathrm{MWep}^{4}$

1. orders of magnitude

a) hard solar total earth' surface involved: $90573394 \mathrm{x}$ $1.74=157.5$ million hectares $(0.38 \%$ of the earth' surface area, 1.74 hectares/MWep)

b) efficiency: $\left(316879 \times 10^{9}\right) /\left(157.5 \times 10^{6}\right) \times 4000=$ 504 TEP / hec, year, stochastic, $\left(104000 \times 10^{9}\right) /$ $\left(157.5 \times 10^{6}\right) \times 4000=165$ TEP / hec, year, stochastic, on demand stored hard solar efficiency $=$ $165 / 504=32.8 \%$

2. 0.95 smart grid 0.95 up-down voltage 0.99 DC-AC, $3900 \mathrm{~h} /$ year at equivalent $5 \mathrm{MWep}$

3 . the number of wind convertors in the regime long duration phase (18182479) is around $1 \%$ of the cars running on the earth's road now

4. equivalent to $20800000 \mathrm{MWe}$ thermoelectric power

\section{Appendix 3. Economy, Investments $\times 10^{9}$ USD}

$\begin{array}{ll}\text { Energy producers } & 156824 \\ \text { Smart grid } & 24 \\ \text { Water elevators } & 292 \\ \text { Electrolytic facility } & 8411 \\ \text { Distilled water storage } & 1117 \\ \text { Condenser } & 300 \\ \text { Pressurized gas storages } & 6882 \\ \text { Others } & 10\end{array}$

$\mathrm{I}=$ Total Investment $173860 \times 10^{9} \mathrm{USD}$

Total cost of concrete or of iron made stakes of wind convertors $15682 \times 10^{9}$ USD

\section{Appendix 4. The Low Cost Economic Strategy (LCS)}

The expenses, table 5 column 2 , are made of the sum of two numbers

$$
\begin{aligned}
& \mathrm{C}=\mathrm{I} / 4=43465 \times 10^{9} \mathrm{USD} \\
& \mathrm{R}=\mathrm{C}-1117 / 4-6882 / 4-15682 / 4+78.45 \times 25 / 4=38036 \times 10^{9}
\end{aligned}
$$
USD

In $\mathrm{R}$ are subtracted the investments which have long amortization time as are the storage facilities and the stakes which sustain gondola and blades of a wind convertor. Amortization costs are added.

The time amortization lenght is 200 years for the wind stakes (hard mainteinance supposed), longer for the storage facilities.

\section{Appendix 5. Oxygen Credit}

(volume of hydrogen) $\times 0.5 \times \eta \times 0.0565$

$$
\eta=\% \text { of oxygen volume sold }
$$

\section{Appendix 6. Diagram of the Modular Storage Facilities}

In Figure 1 are the diagrams of the 11500 modular storage farms of the stored hard solar planetary facility spread on the earth's crust (many of them can be located in the outlying areas of towns, $87 \%$ hydrogen farms, $13 \%$ hydrostorage farms).

A SF captures the stochastic electricity from the smart grid planetary line, and in each SF there are all the facilities (reasumed in Figure 1) to control the production of the stored energy, in each of the two storage methods. The water in is equal to the water out (water conservation).

\section{Appendix 7. Graphic Table of IRG Excess in Atmosphere}

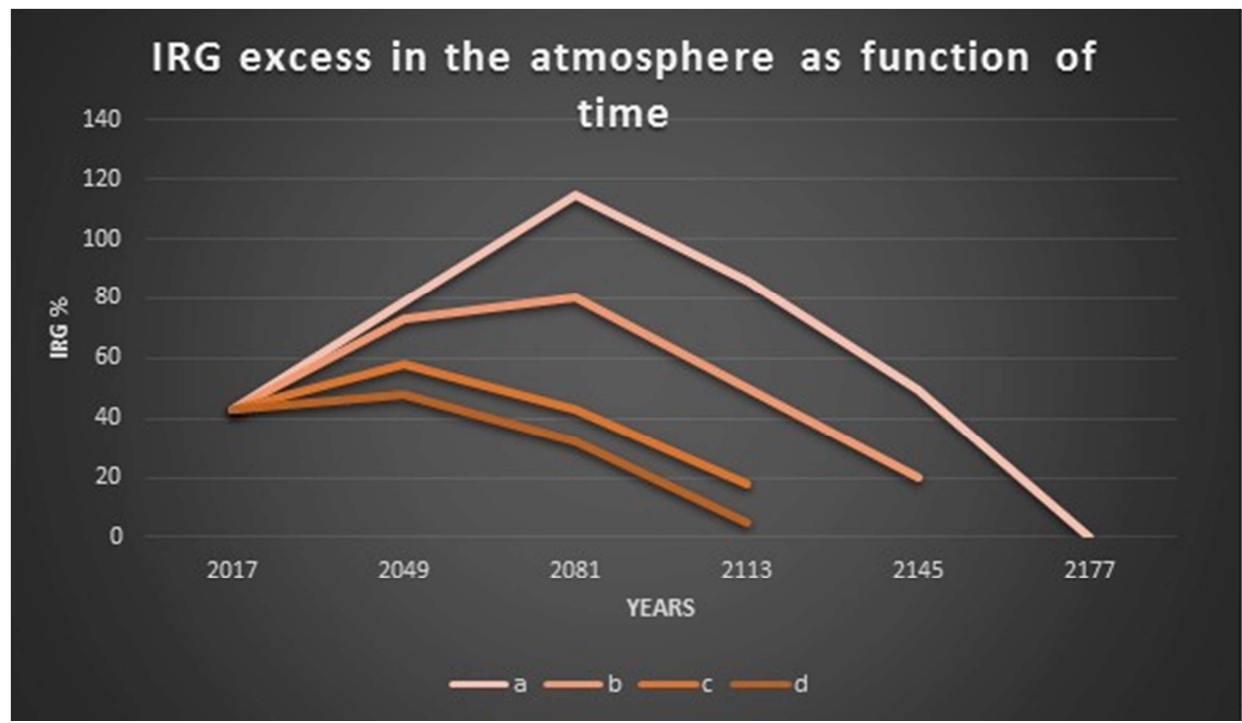

Figure 2. The IRG excess in atmosphere (weigth, \%).
a. IRG excess due to the FDE consumed
b. Regime phase of the whole HSW energetic system after 100 years from start
c. After 50 years
d. After 25 years 


\section{References}

[1] Flohn H., 1981, Life in a warmer earth - Possible climatic consequences of man made global warming, IIASA e.r.

[2] Mac Donald A., 1981, Energy in a finite world, IIASA e.r.

[3] Nardelli E., 1980, I combustibili fossili, carbone, petrolio, gas naturale - Universale ETAS Editor.

[4] Weingart J. M., 1981, The helios strategy - an erethical view of the potential role of the solar energy in the future of a small planet, IIASA e.r.

[5] Bruni G., 1957, Chimica generale ed inorganica - Libreria Editrice Politecnica Cesare Tamburini Milano (aggiornamento, Giorgio Renato Levi e Mario A. Mollier).

[6] Visentin R., 1986, The role of hydrogen in the economy of renewable energetic technologies - VI World Hydrogen Energy Conference Vol. 1 20-24 July 1986, Vienna, Austria.

[7] Visentin R., 1978, Solar energy storage - Analysis of the weather conditions in the Mediterraean area for long term storage of solar energy - 4-8 Sept 1978 Miramare, Trieste International Center of Theoretical Physics P. O. Box 586 Trieste, Italy.

[8] Bellecci C., Conti M., Visentin A., Visentin R., 1979, The energy cost-benefit ratio of parabolic trough with reference to electric power production from solar radiation. CIRAES (Centro Interdipartimentale Ricerca Applicazioni Energia Solare) Calabria University CS Italy - Proceedings of 18th International COMPLES Conference Milano 23-27 Sept 1979 Ed. Sviluppo Cassa di Risparmio di Calabria e Lucania.

[9] Visentin R., 1988, Culture and development strategies for the exploitation of the results of publicy funded research - CEE Utilization of the results of public research and development. Luxemburg 1988 Official Publications Of. EC. ISDN 928258203-5 Catalogue number CD-NA 12243 EN-C printed in Belgium.

[10] Visentin R., 1981, Consiglio Nazionale delle Ricerche Italy. Finalized energy programme 1975-1981 - Subproject Solar Energy - Responsible R. Visentin - 500 researchers from 40 industrial firms, 18 universities, 12 CNR centers.

[11] Barra O., Conti M., Santamato E., Visentin R., 1976, FisicaProblemi e complementi, Meccanica del punto e dei sistemi di punti, Meccanica dei fluidi, Onde elastiche, Termometria e Calorimetria, Termodinamica, sfruttamento Energia solare. Bulzoni Editore srl, Via Liburni 14 Roma Italy p. 580.

[12] Visentin R., 1971, Linee di trasmissione in regime sinusoidale e impulsivo. Bulzoni Editore srl, Via Liburni 14 Roma Italy p. 230.

[13] Visentin R., 1974, Corso di elettronica. Vol. 1 p. 676, Vol. 2 p. 338. Sansoni Editore Firenze, Italy.

[14] Visentin R., 1990, Ambiente risorsa economica della civiltà del 2000. Unesco Club di Verona, Verona, Italy.

[15] Visentin R., 1979, Caro vecchio dio sole. Mensile EURO nuova serie n. 8 (August 1979). Ed. S. e. p. e. Piazza della Libertà 10, Roma, Italy.

[16] Visentin R., 1986, Clima e ambiente risorse economiche della civiltà del 2000. Società Editrice Universo, Via G. B. Morgagni, Roma, Italy.

[17] Visentin R., 1992, PFT-CNR contratto num. 850019-393. Studio di fattibilità volto a definire la cornice tecnologica e tecnoeconomica di un sistema a trazione elettrica alimentato da energia solare diretta e indiretta. 